\title{
Peer-review reciprocity and commitment to manuscript evaluation
}

\author{
Theo C. M. Bakker ${ }^{1}$ - James F. A. Traniello ${ }^{2}$ \\ Published online: 27 February 2019 \\ (C) Springer-Verlag GmbH Germany, part of Springer Nature 2019
}

Ideally, peer review ensures published results of scientific research have been expertly validated without bias and can be trusted. This system of verification is unique to science publishing and central to the evidence-based construction of knowledge. Whether conducted anonymously or with full transparency, commitment to ethically participate in the practice of peer review is required. Invitations to review manuscripts have increased with the burgeoning growth and diversification of science, mirrored in the publication of 2.5 million articles annually (Boon 2017). This places additional demands on time budgets limited by research, writing, teaching, mentoring, and administrative responsibilities.

Peer review only works when authoritative peers are willing to serve as reviewers, and it works best when the number of scientists deciding the fate of a manuscript is not constrained. How can the obligations of peer review be satisfied? What are reasonable expectations for participation in peer review?

There is a professional mutualism among scientists that should be acknowledged, as authors and reviewers alternate roles and in doing so form a reciprocal network of critical analysis. Recognition of responsibility and commitment to participation in this system of scholarship is required. For the system to be self-supporting, resilient, and effective, authors of each manuscript submitted to and reviewed by a peer-review journal should accept two to three (the typical number of reviewers in many journals) requests to review manuscripts in return. In the case of multiple-author papers, which represent the great majority of papers today, it can be difficult to keep track of this important ethical obligation due to the lack of awareness of the reviewing activities of co-authors. Nevertheless, effort should

Theo C. M. Bakker

tbakker@evolution.uni-bonn.de

1 Institute for Evolutionary Biology and Ecology, University of Bonn, An der Immenburg 1, 53121 Bonn, Germany

2 Department of Biology, Boston University, 5 Cummington Mall, Boston, MA 02215, USA be made to maintain the same ratio. Additionally, if a manuscript has been rejected and resubmitted to another journal(s), the number of resubmissions must be considered. For a threeauthor paper that had been submitted to two journals before acceptance, each co-author should be willing to review one to two manuscripts in return. This pattern seems to be characteristic of peer review in regions where science is well established (on average 1.95 reviews/submission), but is clearly lower in emerging regions like China, India, and Turkey (on average 0.66 reviews/submission) (Publons 2018).

The share of manuscript reviewing for high-output scientists is relatively heavy and may be exacerbated by the ever-growing number of papers (Larsen and von Ins 2010; Bornmann and Mutz 2015; Boon 2017; Publons 2018). A high review load and extensive commitments otherwise are indicated as the main reasons for declining an invitation to review a manuscript (Tite and Schroter 2007; Breuning et al. 2015; Willis 2016). Other reasons include mismatch of expertise, conflict of interest, and unavailability (Breuning et al. 2015; Willis 2016; Publons 2018).

For Behavioral Ecology and Sociobiology (BES), the rate of declining an invitation to evaluate a manuscript is increasing (Fig. 1), thereby following the general trend of declining willingness to review (Publons 2018). The reasons for this pattern are complex, but may reflect the general increase in academic workloads of potential reviewers (Publons 2018; Sonne and Alstrup 2019). If more experienced reviewers have increased demands on their time, then manuscripts could be reviewed by less-knowledgeable and less-experienced researchers in the field, potentially contributing to a decline in the quality of published articles (Sonne and Alstrup 2019). None of the reasons to decline an invitation to review can be sanitized; only portable peer review (practiced for instance by Peerage of Science, and for BES mediated by the Springer Transfer Desk) may provide relief as it uncouples peer review from submission to a given journal and thereby reduces redundancy of effort.

Ortega (2017) attempted to explain variation in the willingness to review manuscripts using Publons-registered reviewer 


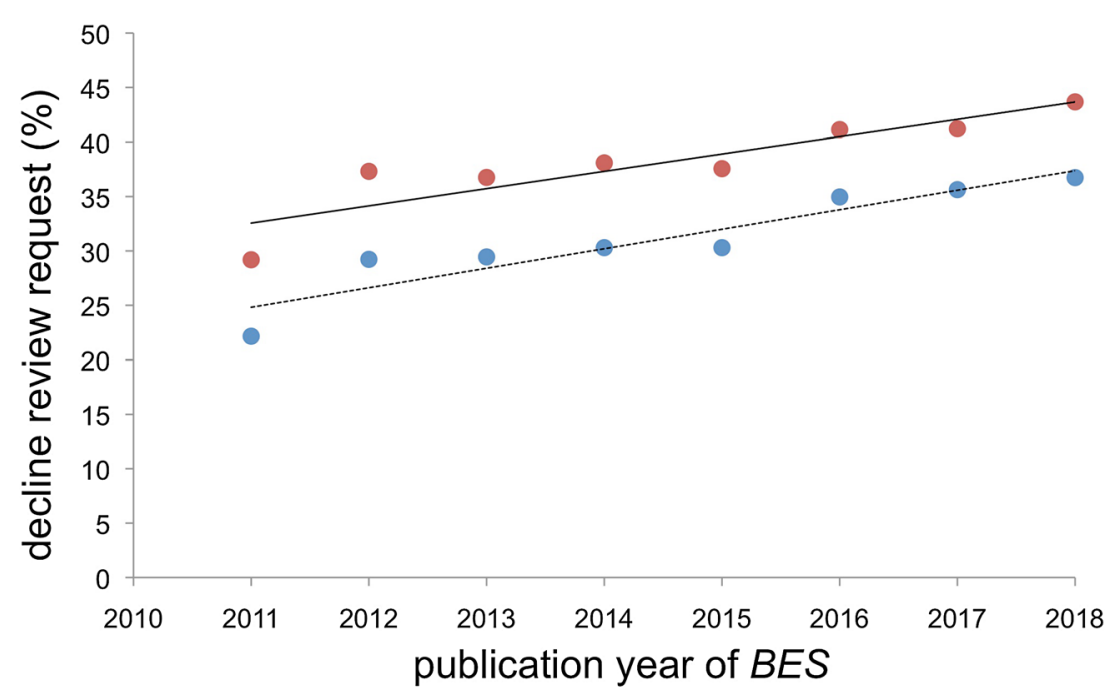

Fig. 1 Change in the rates that invited reviewers declined to accept a review request for manuscripts submitted to Behavioral Ecology and Sociobiology from 2011 to 2018. Declination rates were calculated relative to the number of invited reviewers (1878-2333) (blue data points) and to the sum of the number of reviewers that completed a review and those that declined to review (orange data points). Data

data from the Health Sciences, Physical Sciences and Engineering, Life Sciences and Social Sciences, and Humanities. Only a weak positive correlation (Pearson correlation $<0.1$ ) was found between peer-review activity and reviewer bibliometric performance (number of citations and hindex), and between reviewer productivity and number of reviews (Pearson correlation $=0.204)$. The latter correlation was expected on the basis of a "fair" review share. Most reviews were made by academically established men of varying rank (Ortega 2017). Willingness to review may also be related to journal impact. In a survey of peer reviewers from five biomedical journals, journal reputation was indicated as an important factor to accept, but not to decline, a request to review a manuscript (Tite and Schroter 2007). Variation in the willingness to review may be related to manuscript subfield (Breuning et al. 2015). If journal impact factor is found to influence decisions to decline to review and as a consequence negatively affect the quality of published work, then ethical obligations in peer review should be critically examined.

If the peer-review process is compromised, the consequences will be significant, as the ultimate goal of scientific publishing cannot be guaranteed. Serious threats to the critical and unbiased peer-review system occur, and the emergence of raptorial pseudojournals could become broader and more serious in a socially digital post-truth environment. For example, fake peer review-facilitated by soliciting authors for potential reviewers of their manuscripts (Haug 2015) - has been reported. Such misconduct - more appropriately called fraudsuggests pressures of a "publish or perish" mentality intrinsically linked to appointment, tenure, promotion, funding decisions, and most other criteria for career advancement. were retrieved from the Editorial Manager (EM) electronic submission system. Calculations for 2011 were based on 519 invited reviewers only due to a change in the $B E S$ submission system in September 2011. Linear regressions: orange data points, $y=1.5882 x-3161.2, r^{2}=0.80, F_{1,6}=$ 24.40, $p=0.0026$; blue data points, $y=1.7938 x-3582.5, r^{2}=0.87$, $F_{1,6}=41.25, p=0.0007$

Peer review will remain the golden standard. Alternative publication models such as F1000Research, an open peerreview platform, and publications on preprint-servers like arXiv that stimulate scientific discussion in the research community after posting may increase in importance. Together with invited or unsolicited commentaries in many journals, they contribute to post-publication self-policing.

Can what appears to be inadequate reviewer cooperation be reversed and the nature of reciprocity in peer review be better recognized? Sustained efforts to counter this disappointing and potentially disturbing trend should involve portable peer review, which as mentioned, may reduce reviewer workload. An important step forward will also be made when academic institutions and funding agencies recognize peer-review contributions as a skill and valued metric of scholarship and productivity that is treated more equitably with publication and citation records, rather than marginalized as generic professional service (Publons 2018). Web platforms, like Publons, anticipated the need for referee acknowledgement by offering official certificates for reviewing activity. Reviewers from emerging global communities of science should be encouraged to continue their commitment to the peer-review process. Although underrepresented today most likely due to language, they are more willing to review (invitation acceptance rate of $56.6 \%$ ) than scientists in established regions (49.5\%) (Publons 2018). Additionally, opportunities for training in formal courses and mentoring of doctoral students, post-doctoral associates, and newly appointed faculty in peer review must be enhanced (Schiermeier 2016). 
Acknowledgments We thank Associate Editor Dr. Thomas Madsen, whose invitations to review a single manuscript were declined 14 times, for suggesting this editorial and providing insights. We thank our entire Editorial Board for their dedication, and effectively handling the challenge of securing authoritative manuscript evaluations at a time of declining willingness to review.

\section{Compliance with ethical standards}

Conflict of interest The authors declare that they have no conflict of interest.

Publisher's note Springer Nature remains neutral with regard to jurisdictional claims in published maps and institutional affiliations.

\section{References}

Boon S (2017) 21st Century Science Overload, http://blog. cdnsciencepub.com/21st-century-science-overload/
Bornmann L, Mutz R (2015) Growth rates of modern science: a bibliometric analysis based on the number of publications and cited references. J Assoc Inf Sci Technol 66:2215-2222

Breuning M, Backstrom J, Brannon J, Gross BI (2015) Reviewer fatigue? Why scholars decline to review their peers' work. PS-Polit Sci Polit 48:595-600

Haug CJ (2015) Peer-review fraud - hacking the scientific publication process. N Engl J Med 373:2393-2395

Larsen PO, von Ins M (2010) The rate of growth in scientific publication and the decline in coverage provided by science citation index. Scientometrics 84:575-603

Ortega JF (2017) Are peer-review activities related to reviewer bibliometric performance? A scientometric analysis of Publons. Scientometrics 112:947-962

Publons (2018) Global state of peer review 2018, https://doi.org/10. 14322/publons.GSPR2018

Schiermeier Q (2016) Peer review: close inspection. Nature 533:279-281

Sonne C, Alstrup AKO (2019) Discussion: Peer-review under siege. Sci Total Environ 651:1180-1181

Tite L, Schroter S (2007) Why do peer reviewers decline to review? A survey. J Epidemiol Community Health 61:9-12

Willis M (2016) Why do peer reviewers decline to review manuscripts? A study of reviewer invitation responses. Learn Publ 29:5-7 